\title{
Actin enhances the haemolytic activity of Escherichia coli
}

\author{
R. J. Basaraba, ${ }^{1}$ A. N. Byerly, ${ }^{1}$ G. C. Stewart, ${ }^{1}$ D. A. Mosier, ${ }^{1}$ \\ B. W. Fenwick, ${ }^{1}$ M. M. Chengappa ${ }^{1}$ and W. W. Laegreid ${ }^{2}$
}

Author for correspondence: R. J. Basaraba. Tel: +1 7855324456. Fax : +1 7855324481.
e-mail : basaraba@vet.ksu.edu

1 Department of Diagnostic Medicine/Pathobiology, College of Veterinary Medicine, VCS Building. 1800 Denison Avenue, Kansas State University, Manhattan, KS 665065601, USA

2 United States Meat Animal Research Center, Clay Center, NE, USA

\begin{abstract}
Actin is a major cytoskeletal protein of mammalian muscle and non-muscle cells. Exposure of cells to soluble factors that damage cell membranes results in the release of actin into the extracellular spaces. The $\alpha$-haemolysin (HlyA) of Escherichia coli is the prototype RTX (repeat in toxin) toxin and is thought to be important in virulence because of its ability to lyse cells by formation of pores in the cell membrane. These studies were conducted to determine if actin influences growth and haemolytic activity of $E$. coli. Growth of $E$. coli in the presence of actin resulted in culture supernatant haemolytic activity that was 2.4-, 2.7- and 3.3-fold greater than that of E. coli grown in medium containing BSA, non-supplemented medium, or medium containing heatdenatured actin, respectively. The enhanced haemolytic activity occurred only when actin was present during the growth phase and there was no effect when actin was added to culture supernatants containing haemolysin. The increased haemolytic activity by actin was concentration-dependent, detectable in early-exponential-phase growth, and associated with increased concentrations of secreted HlyA by Western blotting. Actin induced a 2.9-fold increase in alkaline phosphatase activity in E. coli CC118 with a TnphoA insertion in the hlyB determinant of the recombinant haemolysin plasmid pWAM04. These results indicate that extracellular actin enhances haemolysin production by $E$. coli and may have implications in the pathogenesis of $E$. coli infections.
\end{abstract}

Keywords : actin, Escherichia coli, haemolysin

\section{INTRODUCTION}

Actin is the predominant protein of the microfilament cytoskeleton and the most abundant intracellular protein in mammalian cells. Actin accounts for $10-20 \%$ of protein in most cells and as much as $35 \%$ of total protein in platelets (Harris \& Weeds, 1978; Pollard \& Cooper, 1986; Stossel, 1978). Actin exists in two intracellular pools, soluble monomers (globular or Gactin) or polymerized filaments (filamentous or F-actin) (Cooper, 1991; Theriot, 1994). When soluble actin is released from damaged cells, polymerization is favoured in the presence of increased extracellular salt concentrations (Haddad et al., 1990). Excessive cell damage from tissues undergoing necrosis or severe inflammation can result in the release of relatively large quantities of actin into the extracellular space and peripheral cir-

Abbreviations: FBS, foetal bovine serum; SRBC, sheep red blood cell. culation (Goldschmidt-Clermont et al., 1988; Lee et al., 1985; Smith et al., 1988). An actin-scavenger system composed of actin-binding and actin-severing proteins is present in serum of humans and animals and serves to remove extracellular actin (Dueland et al., 1991; Harris et al., 1980; Lee \& Galbraith, 1992). Depletion of the actin-scavenger system can result in accumulation of extracellular actin, thus contributing to increased blood viscosity, endothelial damage, microvascular thrombosis and delayed clearance of inflammatory exudate (Haddad et al., 1990; Vasconcellos et al., 1994).

Escherichia coli $\alpha$-haemolysin ( $\mathrm{HlyA}$ ) is the prototype of the RTX (repeat in toxin) family of bacterial toxins (Felmlee et al., 1985; Welch et al., 1992). Gram-negative bacterial pathogens of humans and animals that produce structurally similar RTX toxins include Actinobacillus actinomycetemcomitans (Kolodrubetz et al., 1989; Kraig et al., 1990), Pasteurella haemolytica, Actinobacillus pleuropneumoniae, Proteus vulgaris and 
Morganella morganii (Devenish et al., 1989; Eberspacher et al., 1990; Koronakis et al., 1987). Certain RTX toxins are host-specific and cytolytic against a narrow range of target cells, while $E$. coli haemolysin is toxic to a wide range of mammalian cell types (Beutin, 1991; Bhakdi et al., 1990; Cavalieri \& Snyder, 1982; Forestier \& Welch, 1991; Trifillis et al., 1994). The sublethal effects of HlyA on leucocytes include depletion of ATP and the release of inflammatory mediators and cytokines from leucocytes and platelets (Bhakdi et al., 1990; Cavalieri \& Snyder, 1982; Konig et al., 1994). The cytotoxic activity of HlyA, as with other RTX toxins, results from the formation of 1-2 nm, cation-specific, transmembrane pores that result in leakage of the cytoplasmic membrane, osmotic swelling and cell lysis (Konig et al., 1994; Menestrina et al., 1994; Moayeri \& Welch, 1994).

One consequence of cytolysis is the release of intracellular contents, including cytoplasmic proteins, into the extracellular space (Clinkenbeard et al., 1989). Exposure of a susceptible cell line (BL3) to culture supernatants from E. coli, $P$. haemolytica and $A$. pleuropneumoniae results in the release of actin into culture supernatants (R. J. Basaraba \& A. N. Byerly, unpublished results). During infections, host proteins like actin may interact with bacteria within inflammatory exudate and further influence bacterial pathogenicity. However, the effect that actin and other host proteins have on bacterial virulence factor expression, specifically RTX toxins, has not been adequately investigated (Clinkenbeard et al., 1995; Waurzyniak et al., 1994). In these studies, we show that actin enhances the expression of HlyA by E. coli.

\section{METHODS}

Bacteria and plasmids. Escherichia coli, strain K-12, CC118

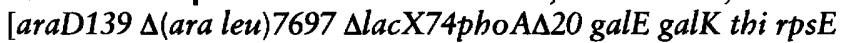
$r p o B \arg E_{\mathrm{am}}$ recA1 (Manoil \& Beckwith, 1985) was used as the host strain for TnphoA mutagenesis. The haemolysin recombinant plasmid pWAM04 (provided by Dr Rodney Welch, University of Wisconsin, USA) carries the blyCABD genes that convey a haemolytic phenotype to host bacteria (Welch \& Pellett, 1988). E. coli 5-20701 (O138: F:107 H14W, $\mathrm{Sta}^{+}$and $\mathrm{Stb}^{-}$) was isolated from the faeces of a pig with diarrhoea. Bacteria were grown on sheep blood agar and colonies were resuspended to an $\mathrm{OD}_{570}$ of 0.250 in $0.01 \mathrm{M}$ PBS $(0.145 \mathrm{M}$ $\mathrm{NaCl} ; 0.15 \mathrm{M}$ sodium phosphate). Bacterial suspensions $\left(100 \mu \mathrm{l}, 1.3 \times 10^{6}\right.$ c.f.u. $\left.\mathrm{ml}^{-1}\right)$ were inoculated into $30 \mathrm{ml} \mathrm{RPMI-}$ 1640 medium with or without $0.1 \%$ foetal bovine serum (FBS) (Sigma) and incubated for $6 \mathrm{~h}$ at $37^{\circ} \mathrm{C}$ on a rotary shaker. Bacteria were removed by centrifugation at $16000 \mathrm{~g}$ for $1 \mathrm{~min}$ and the supernatant was filtered through $0.22 \mu \mathrm{m}$ pore-size acetate syringe filters (MSI, Micron Separations) and stored at $-70^{\circ} \mathrm{C}$.

Actin. Actin was purified from bovine skeletal muscle using the method of Spudich \& Watt (1971). Purified bovine skeletal muscle actin in buffer A $(2 \mathrm{mM}$ Tris $/ \mathrm{HCl}, 0.2 \mathrm{mM} \mathrm{Na} 2 \mathrm{ATP}$, $0.5 \mathrm{mM}$ 2-mercaptoethanol, $0.2 \mathrm{mM} \mathrm{CaCl}{ }_{2}, \mathrm{pH} 8.0$ ) was filtersterilized, polymerized by dialysis in $0.01 \mathrm{M}$ PBS, and stored as $\mathrm{F}$-actin at $4^{\circ} \mathrm{C}$ at a concentration greater than $10 \mathrm{mg} \mathrm{ml}^{-1}$. Gactin was prepared by dialysis of F-actin in buffer $\mathrm{A}$ and by centrifugation for $30 \mathrm{~min}$ at $100000 \mathrm{~g}$ to remove residual F- actin. G-actin was lyophilized in the presence of $2 \mathrm{mg}$ sucrose (mg actin $)^{-1}$ and stored at $-70^{\circ} \mathrm{C}$ for long-term storage (Frieden, 1982). Protein concentrations were determined using the Pierce Micro BCA assay.

Culture conditions. Thirty millilitre aliquots of RPMI-1640 medium containing either F-actin, heat denatured F-actin, Gactin or BSA fraction V (ICN Biomedicals) $\left(30 \mu \mathrm{g} \mathrm{m}^{-1}\right)$ were inoculated with $E$. coli $5-20701\left(1.3 \times 10^{6}\right.$ c.f.u. $\left.\mathrm{ml}^{-1}\right)$ and incubated at $37^{\circ} \mathrm{C}$ on a rotary shaker. Aliquots of bacterial suspension were removed from 0 to $12 \mathrm{~h}$ at $2 \mathrm{~h}$ intervals and at $24 \mathrm{~h}$. Bacteria were removed by centrifugation and the supernatants were filtered and stored at $-70^{\circ} \mathrm{C}$ until assayed for haemolytic activity.

To determine the influence of FBS supplementation on haemolytic activity, E. coli was grown for 6 h in RPMI-1640 or RPMI- 1640 supplemented with $0 \cdot 1 \%$ FBS and/or $30 \mu \mathrm{g} \mathrm{F-}$ actin $\mathrm{ml}^{-1}$. Bacteria were removed by centrifugation and the supernatant was filtered and stored at $-70^{\circ} \mathrm{C}$ until assayed for haemolytic activity.

The effect of various actin concentrations was evaluated with parallel cultures of $E$. coli in RPMI-1640 containing $0.1 \%$ FBS supplemented with $0-50 \mu \mathrm{g} \mathrm{F}$-actin $\mathrm{ml}^{-1}$. Haemolytic activity of $6 \mathrm{~h}$ sterile filtered culture supernatants was determined for each actin concentration.

In separate experiments, F-actin $\left(30 \mu \mathrm{g} \mathrm{ml}^{-1}\right)$ was added to culture supernatants of RPMI-1640 and RPMI-1640 supplemented with $0.1 \%$ FBS prior to assaying for haemolytic activity.

Haemolysin assay. Haemolytic activity of culture supernatants was determined by lysis of $1 \%$ sheep red blood cell (SRBC) suspensions (Feder et al., 1994). Whole sheep blood was collected in heparin, washed in PBS by centrifugation, and stored at $4^{\circ} \mathrm{C}$ at a packed cell volume of $10-15 \%$ in citratephosphate-dextrose $\left(280-300 \mathrm{mOsm} \mathrm{kg}^{-1}\right)$. A standard curve of haemolytic activity was constructed by adding $0,2,5,10$, $20,30,50,70,90$ and $100 \mu l$ culture supernatants and the final volume of each well was adjusted to $100 \mu \mathrm{l}$ with RPMI-1640 medium. For each assay, $100 \mu \mathrm{l}$ of a $1 \%$ suspension of SRBCs in $10 \mathrm{mM} \mathrm{Tris} / \mathrm{HCl} /$ saline, $\mathrm{pH} 7 \cdot 4$, was placed in triplicate wells of V-bottom 96-well microtitre plates (Dynatech Laboratories). Plates were incubated for $2 \mathrm{~h}$ at $37^{\circ} \mathrm{C}$, centrifuged for $5 \mathrm{~min}$ at $80 \mathrm{~g}$, and $100 \mu \mathrm{l}$ supernatant was transferred to flatbottom 96-well microtitre plates (Corning). The haemoglobin content was determined by measuring the $A_{410}$ using a microplate reader (V Max microplate reader; Molecular Devices). Relative haemoglobin concentrations were compared to the maximal haemoglobin release following osmotic lysis of SRBCs with distilled water.

Haemolysis was expressed as the $A_{410}$ or the reciprocal of the haemolytic units, where one haemolytic unit equals the microlitres of culture supernatant required to lyse $50 \%$ of a $100 \mu \mathrm{l}$ volume of a $1 \%$ suspension of SRBCs (Feder et al., 1994). The number of haemolytic units in the culture supernatant was calculated from the standard curve using the ELISA plate reader software (Softmax; Molecular Devices).

Bacterial growth. Growth kinetics of $E$. coli were evaluated in parallel cultures in RPMI-1640 containing 0.1\% FBS supplemented with F-actin, heat-denatured F-actin or BSA $(30 \mu \mathrm{g}$ $\mathrm{ml}^{-1}$ ). Cultures were grown at $37^{\circ} \mathrm{C}$ on a rotary shaker and aliquots for plate counts and $\mathrm{OD}_{570}$ measurement were obtained at $2 \mathrm{~h}$ intervals from 0 to $24 \mathrm{~h}$.

Electrophoresis and Western blot analysis. Culture supernatants were concentrated $20 \times$ (Centricon 30; Amicon), boiled in electrophoresis buffer, subjected to SDS-PAGE using 
$4 \%$ stacking and $7.5 \%$ resolving gels, and electrophoretically transferred to nitrocellulose membranes. Membranes were incubated with pooled anti-HlyA mAbs B7 and C10 $(1: 10000$ and 1:5000, respectively) provided by Dr Rodney Welch (Pellett $e$ t al., 1990). Actin-antibody complexes were detected by sequential reaction of membranes with anti-mouse antibody conjugated with horseradish peroxidase (Sigma), followed by 4-chloro-4-naphthol for colour development.

TnphoA mutagenesis. Plasmid pWAM04 was introduced into E. coli $\mathrm{CC} 118$ by transformation. TnphoA mutagenesis was carried out on this strain by the methods of Manoil \& Beckwith (1985). Kanamycin-resistant, alkaline-phosphatasepositive colonies were plated on blood agar to assess the haemolytic phenotype and on Luria agar that contained ampicillin to monitor retention of the plasmid. Strains which were resistant to kanamycin and ampicillin and were nonhaemolytic were selected. Plasmid DNA was isolated by the method of Birnboim \& Doly (1979). The site of insertion of Tn $p h o A$ was determined by DNA sequence analysis using the f-mol kit (Promega) and a primer specific to the $p h o A$-end of TnphoA. One isolate, NH1, which contained a TnphoA insertion within bly $B$ was selected. The alkaline phosphatase spectrophotometric assays were carried out as described by Manoil \& Beckwith (1985).

Data analysis. Data were analysed by repeated measures analysis and analysis of variance using SAS version 6.11 (SAS Institute, Cary, NC, USA). Tests for significance were by protected least significant differences.

\section{RESULTS}

\section{Influence of actin on haemolytic activity}

The haemolytic activity of $E$. coli culture supernatants increased in a time-dependent fashion with peak activity between 8 and $12 \mathrm{~h}$ (Fig. 1). The relative trends for rate

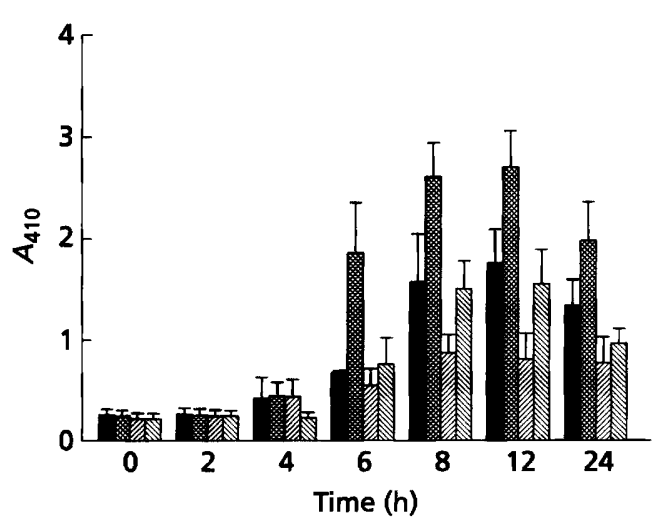

Fig. 1. Comparison of haemolytic activity of culture supernatants of $E$. coli grown in the presence of protein supplements. The haemolytic activity of culture supernatants of $E$. coli grown in the presence of F-actin ( $\otimes)$, heat-denatured

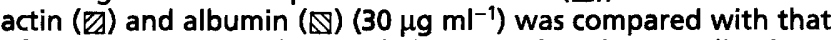
of non-supplemented RPMI ( $\square$ ). Haemolysis by $E$. coli culture supernatant was expressed as haemoglobin released from lysed SRBCS incubated with undiluted culture supernatant. Treatments from each experiment were done in triplicate and averaged. Data represent the mean of four separate experiments \pm SEM.

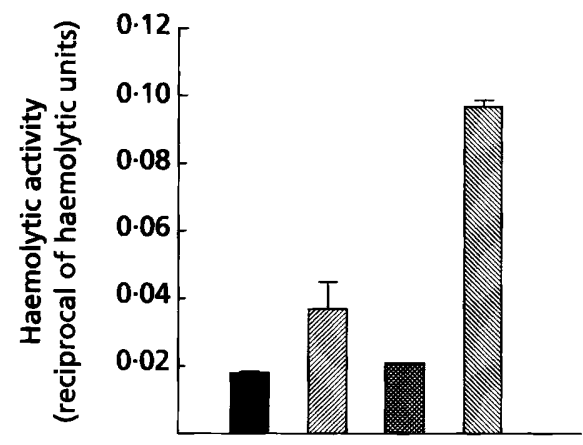

Fig. 2. Synergistic effect of serum and actin on the haemolytic activity of $E$. coli culture supernatants. The figure shows the haemolytic activity of culture supernatant of $E$. coli grown in

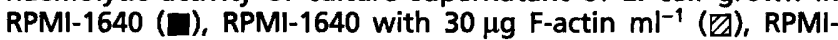
$1640+0.1 \%$ FBS (B) or RPMI- $1640+0.1 \%$ FBS and $30 \mu \mathrm{g}$ F-actin $\mathrm{ml}^{-1}(\mathbb{\nabla})$. Treatments from each experiment were done in triplicate and averaged. The data represent the mean of four separate experiments \pm SEM.

of increase and the decline in haemolytic activity were similar for all treatments. However, at $6 \mathrm{~h}$ growth, culture supernatants containing actin had $2 \cdot 7,2 \cdot 4$ and 3.3 times more haemolytic activity than RPMI-1640, RPMI-1640 supplemented with BSA, and RPMI-1640 supplemented with heat-denatured actin, respectively. These differences were significant $(P \leqslant 0.01)$ at 6 as well as $8 \mathrm{~h}$. At $12 \mathrm{~h}$, actin-supplemented cultures differed only from those supplemented with heat-denatured actin $(P \leqslant 0.01)$. No significant differences were present between RPMI-1640 and RPMI-1640 supplemented with either heat-denatured actin or BSA at any time point.

Supplementation of RPMI-1640 containing $0 \cdot 1 \%$ FBS with actin increased the haemolytic activity of $E$. coli supernatant $4 \cdot 6$-fold compared to supernatant from RPMI-1640 containing only $0 \cdot 1 \%$ FBS (Fig. 2). Supplementation of cultures with $0.1 \%$ FBS did not enhance the haemolytic activity compared to RPMI-1640 alone. Addition of $30 \mu \mathrm{g}$ actin $\mathrm{ml}^{-1}$ to cultures grown in RPMI1640 medium increased the haemolytic activity $2 \cdot 6$-fold compared to non-supplemented RPMI-1640 cultures.

Actin-mediated enhancement of $E$. coli haemolysin activity in RPMI-1640 containing $0.1 \%$ FBS was concentration-dependent (Fig. 3). There was no significant difference $(P \geqslant 0.05)$ in haemolytic activity of culture medium with $0,1,5$ and $10 \mu \mathrm{g}$ actin $\mathrm{ml}^{-1}$. Differences were significant $(P \leqslant 0.05)$ when actin was added at $20 \mu \mathrm{g} \mathrm{ml}^{-1}$ or greater, with maximal haemolytic activity at $30 \mu \mathrm{g}$ actin $\mathrm{ml}^{-1}$. There was a slight decrease in haemolytic activity at $50 \mu \mathrm{g}$ actin $\mathrm{ml}^{-1}$, although differences were not significant $(P \geqslant 0.05)$. E. coli culture supernatant supplemented with a 10 -fold higher actin concentration $\left(300 \mu \mathrm{g} \mathrm{ml}^{-1}\right)$ had haemolytic activity similar to $30 \mu \mathrm{g} \mathrm{ml}^{-1}$ and $50 \mu \mathrm{g} \mathrm{m}^{-1}$ samples (data not shown).

Addition of $30 \mu \mathrm{g}$ actin $\mathrm{ml}^{-1}$ to supernatants of E. coli grown in RPMI- 1640 alone or RPMI-1640 with $0 \cdot 1 \%$ 


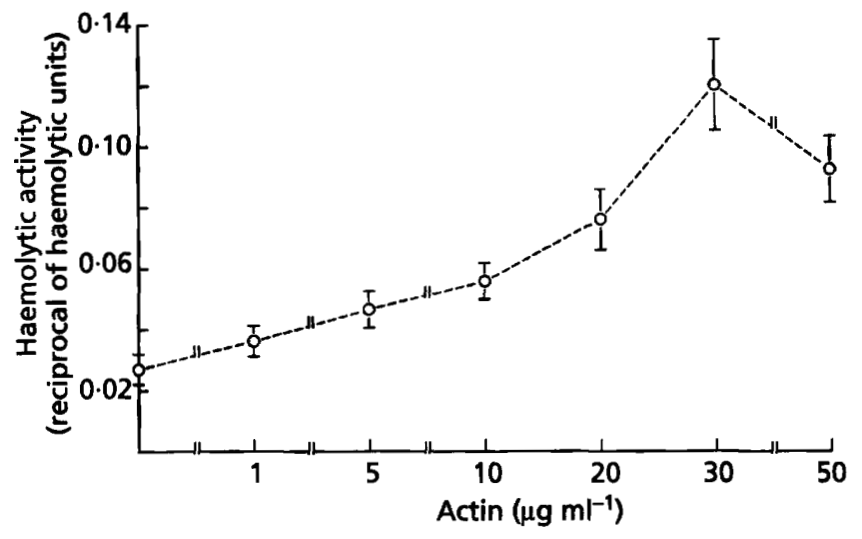

Fig. 3. Actin-concentration-dependent expression of $E$. coli haemolytic activity. $E$. coli was grown in the presence of RPMI$1640+0.1 \%$ FBS to which increasing concentrations of F-actin were added. The haemolytic activity of culture supernatant was determined by the haemoglobin released from the lysis of SRBCs. Data represent the mean of samples done in triplicate, averaged from five separate experiments \pm SEM.

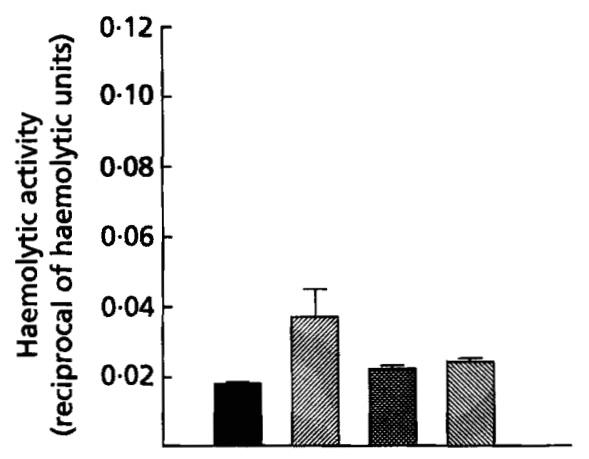

Fig. 4. Failure of actin to influence haemolytic activity of preformed haemolysin in $E$. coli culture supernatant. The haemolytic activity of culture supernatant of $E$. coli grown in the presence of RPMI-1640 supplemented with $30 \mu \mathrm{g}$ F-actin $\mathrm{ml}^{-1}(\mathbb{Z})$ was enhanced compared to that of $E$. coli grown in RPMI-1640 alone (D), RPMI-1640+0.1\% FBS (ख) or RPMI-1640 containing $0.1 \%$ FBS to which $30 \mu \mathrm{g} \mathrm{F}$-actin $\mathrm{ml}^{-1}$ was added (\$), prior to incubation with SRBCs. Data represent the mean of triplicate samples averaged from four separate experiments \pm SEM.

FBS immediately prior to the assay had no additional influence on the haemolytic activity (Fig. 4).

\section{Effect of actin on E. coli growth}

There were no significant differences in the growth of $E$. coli in supplemented and non-supplemented RPMI-1640 medium throughout the growth period. For $6 \mathrm{~h}$ cultures, the $\mathrm{OD}_{570}$ was $0.253,0.254,0.256$ and 0.248 in RPMI1640, RPMI-1640 supplemented with F-actin, RPMI1640 with heat-denatured actin and RPMI-1640 supplemented with albumin, respectively. These data were

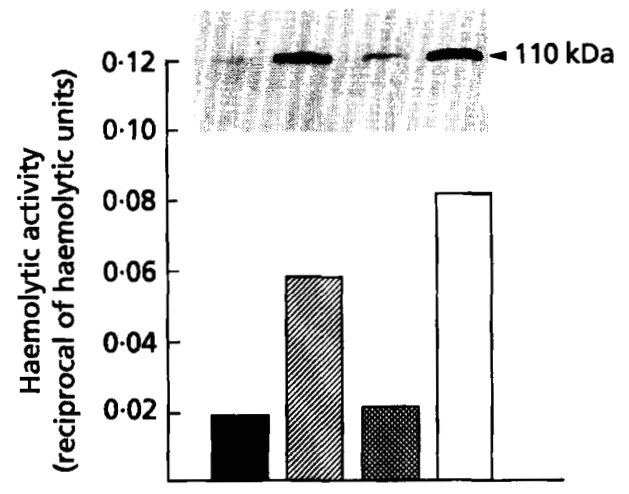

Fig. 5. Actin-mediated enhancement of haemolytic activity corresponds to increased HlyA secretion. The lower panel shows the enhanced haemolytic activity by actin from a representative experiment (lower panel), and the corresponding Western blot analysis of culture supernatant shows increased immunoreactivity to HlyA (upper panel). $E$. coli was grown in RPMI-1640 (回), RPMI-1640+30 $\mu \mathrm{g}$ F-actin $\mathrm{ml}^{-1}$ (घ), RPMI$1640+0.1 \%$ FBS (ख) or RPMI- $1640+0.1 \%$ FBS $+30 \mu \mathrm{g}$ F-actin $\mathrm{ml}^{-1}(\square)$. Each lane in the upper panel contains the equivalent of $2 \mathrm{ml}$ concentrated supernatant.

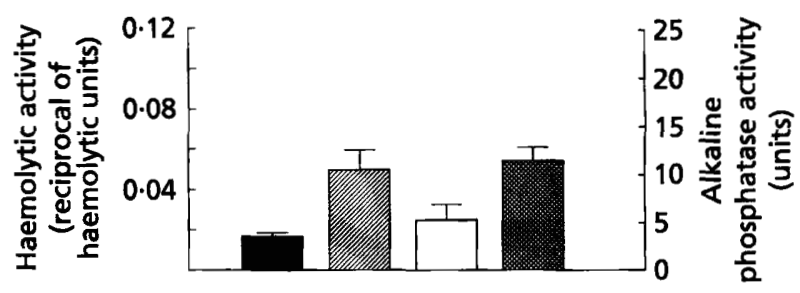

Fig. 6. Enhanced expression of HlyB-alkaline phosphatase fusion protein in $\mathrm{NH} 1$ grown in the presence of actin. The $E$. coli strain NH1 carries a copy of TnphoA in hlyB of the recombinant plasmid pWAM04, generating an HlyB-alkaline phosphatase fusion protein. Growth of $\mathrm{NH1}$ in the presence of F-actin (因) enhanced the alkaline phosphatase activity 2.9-fold compared to NH1 grown in RPMI-1640 alone ( $\square)$. E. coli strain CC118 containing the recombinant pWAM04 plasmid without the TnphoA insertion served as a control and haemolytic activity of culture supernatant was determined following growth in RPMI-1640 alone ( $\square$ ) or in RPMI-1640 supplemented

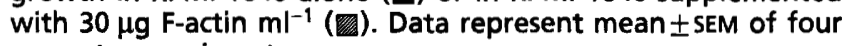
separate experiments.

confirmed with plate counts from a representative experiment (data not shown).

\section{Electrophoresis and Western blot analysis}

Representative culture supernatants with differing haemolytic activities were subjected to SDS-PAGE and immunoblot analysis (Fig. 5). A single band of $110 \mathrm{kDa}$ was detected in $E$. coli culture supernatants by pooled mAbs B7 and C10. Culture supernatants supplemented with F-actin or F-actin and FBS had the greatest haemolytic activity (Fig. 5, lower panel) and the greatest relative concentration of HlyA as represented by band density (Fig. 5, upper panel). 


\section{TnphoA mutagenesis}

E. coli strain NH1 carries a copy of $\operatorname{Tn} p h o A$ in $h l y B$ generating a HlyB-alkaline phosphatase fusion protein. In strain $\mathrm{NH} 1$, expression of alkaline phosphatase is under the control of the blyCABD operon regulatory signals. When NH1 was tested for response to actin, it had a 2-9-fold increase in alkaline phosphatase activity when grown in the presence of F-actin, compared to when grown in RPMI-1640 alone (Fig. 6). E. coli strain CC118 containing the recombinant bly plasmid pWAM04 without the $\operatorname{Tn} p h o A$ insert, grown in the presence or absence of F-actin, was included as a control and had no measurable alkaline phosphatase activity but had comparable haemolytic activity that was $2 \cdot 2$-fold greater in the presence of actin than that of bacteria grown in RPMI-1640 alone.

\section{DISCUSSION}

This study demonstrates that the haemolytic activity of E. coli culture supernatant was enhanced when bacteria were grown in the presence of actin. This enhancement was not due to an effect on bacterial growth, but was associated with increased secretion of HlyA in culture supernatants. The dose responsiveness and the saturation of the effect by high concentrations of actin are consistent with an influence of actin on haemolysin production and secretion rather than changes in HlyA stability or the effects on $E$. coli growth from the added protein. The effect of actin on E. coli haemolysin secretion is particularly relevant since actin is ubiquitous and is released from intracellular pools following cell damage, including that from pore-forming cytotoxins such as HlyA (R. J. Basaraba \& A. N. Byerly, unpublished results).

When haemolytic activity was examined over time, actin-supplemented cultures had increased activity at all time points compared to non-supplemented and BSAand heat-denatured-actin-supplemented cultures. Haemolytic activity declined at a rate that was similar for all treatments, suggesting that the differences in haemolytic activity between treatments were not due to differences in rate of degradation or changes in haemolysin stability. Proteins, chaotropic agents or cations may stabilize HlyA and similar toxins or prevent the self-aggregation of these proteins, thus increasing the active concentration in solution (Clinkenbeard et al., 1995; Confer \& Durham, 1992; Gentry et al., 1986; Rennie et al., 1974; Waurzyniak et al., 1994). Calcium pretreatment of HlyA changes irregular toxin aggregates to regular spherical structures (Rennie et al., 1974). Calcium also activates HlyA and is necessary for binding of haemolysin to erythrocytes and thus influences activity as a posttranslational modification (Boehm et al., 1990). Interestingly, calcium is an integral part of the actin protein structure and may therefore interact with HlyA through its calcium-binding sites (Frieden, 1982). A variation in free calcium concentration in these studies appeared to have no significant influence on haemolytic activity when treatments were compared to media controls. Actin preparations were dialysed and polymerized in a calcium-free PBS buffer prior to use to avoid the influence of changes in extracellular cation concentrations.

To determine if actin influenced haemolytic activity by interacting directly with HlyA or target cells, actin was added to culture supernatant containing haemolysin immediately prior to assaying for haemolytic activity. The lack of effect of actin on haemolysin post-secretion suggests that $\mathrm{F}$-actin has its influence at the time HlyA is produced in the early growth phase or immediately following secretion.

A specific effect of F-actin on E. coli haemolytic activity is suggested by the loss of its influence when denatured by heat and by the significant increase in activity when monomeric $\mathrm{G}$-actin is polymerized to $\mathrm{F}$-actin. This observation has in vivo relevance since extracellular bacteria are probably exposed to higher concentrations of F-actin at sites of inflammation or tissue necrosis (Vasconcellos et al., 1994). G-actin within the cytoplasm is soluble and is released from damaged cells, while Factin is insoluble and closely associated with cell membranes (Cano et al., 1992; Fechheimer \& Zigmond, 1993). Polymerization of G-actin to F-actin is favoured, however, in the presence of high salt concentrations that exist in extracellular spaces (Haddad et al., 1990; Vasconcellos et al., 1994). Therefore, purified G-actin in these studies was polymerized by dialysis against PBS containing physiological salt concentrations.

The synergistic effect between actin- and serumsupplemented medium was unexpected. A concentration of serum was chosen that, when added to culture medium, had no effect on bacterial growth or haemolytic activity. However, when actin was added to the serumcontaining medium, haemolytic activity increased significantly. Serum contains the actin-binding and scavenger proteins gelsolin and vitamin-D-binding protein (GC-globulin) (Lee \& Galbraith, 1992; Lind et al., 1986). Besides binding actin monomers and severing actin filaments, gelsolin is a potent actin nucleating protein thus favouring polymerization. Actin-binding proteins under these conditions may interact with actin and further influence actin polymerization thus amplifying the effect of F-actin on haemolysin activity (Lind et al., 1986). The effect of actin on haemolytic activity is dependent on the form of actin since incubation of $E$. coli in the presence of actin in the G-form has no effect on haemolytic activity.

To establish that the enhanced haemolytic activity by F-actin was not due to nutrient enrichment, E. coli growth rate was compared in the presence of equal concentrations of BSA, heat-denatured actin and nonsupplemented media. The similarity in the rate of bacterial growth between protein-supplemented and non-supplemented culture media indicated that F-actin had little influence on growth, yet significantly influenced expression of haemolytic activity of the culture supernatant.

Western blot analysis of culture supernatants was used 
to determine if $\mathrm{F}$-actin-enhanced haemolytic activity was associated with increased secretion of HlyA in the culture supernatant. The relative increase in immunoreactivity of $\mathrm{HlyA}$ in supernatants containing actin was consistent with increased HlyA concentration rather than a change in activity of secreted HlyA caused by Factin. Although haemolytic activity is generally related to HlyA concentration, extracellular haemolysin can be inactivated without significant degradation of the HlyA protein (Oropeza-Wekerle et al., 1989; Rennie et al., 1974). This loss of haemolytic activity is partially due to a lack of binding of HlyA to target cells (Boehm et al., 1990; Oropeza-Wekerle et al., 1989). Culture supernatants with equal HlyA concentrations could therefore differ in haemolytic activity. However, an increase in haemolytic activity in actin-supplemented culture supernatants in these studies was associated with an increase in HlyA production that was reflected in the culture supernatant as increased HlyA immunoreactivity.

The secretion of active, extracellular HlyA requires the expression of four genes ( $b l y C A B D$ ) constituting the bly operon (Welch et al., 1992). An alteration in the expression of one or more of these gene products required for active transport or activation of HlyA would be reflected in the expression of haemolytic activity in the culture supernatant. Additionally, posttranslational modifications of secreted protein can alter haemolytic activity (Boehm et al., 1990; OropezaWekerle et al., 1989). The insertional mutagenesis of the bly operon by TnphoA enabled the use of this reporter to confirm that growth of $E$. coli in the presence of actin induced the expression of the genes and thus production of HlyA. These data support the Western blot data, indicating that the increased secretion of $\mathrm{HlyA}$ was due to increased production of $\mathrm{HlyA}$ in response to actin supplementation. Furthermore, the increased alkaline phosphatase fusion protein concentration in response to F-actin indicates that the actin enhancement effect is not an artifact of the haemolysis assay. The laboratory strain of E. coli, CC118, carrying the pWAM04 recombinant haemolysin plasmid showed a similar increased response to F-actin both in the haemolysin assay and with the TnphoA insertion as did pathogenic E. coli isolates. These data suggest that the ability of $E$. coli to respond to F-actin is common to at least those pathogenic and laboratory strains that carry the bly genes.

The concentration responsiveness of actin-associated haemolytic activity, the saturation by high actin concentrations, the loss of activity by heat denaturation and the induction of HlyA production in response to actin suggest specific binding of actin to surface-exposed structures on bacterial cells. Such an interaction has been described for Listeria monocytogenes and Shigella flexneri, which express specific actin-binding outermembrane proteins that are important in virulence. The outer-membrane proteins ActA of $L$. monocytogenes and IcsA of $S$. flexneri induce polymerization of cytoplasmic actin and the formation of actin tails used for intracellular motility and cell invasion (Bernardini et al., 1989; Goldberg \& Sansonetti, 1993; Kocks et al., 1992).
The interaction between actin and surface structures of E. coli is supported by preliminary studies in our laboratory showing that certain pathogenic strains induce polymerization of G-actin in solution. However, attempts to demonstrate surface-bound polymerized actin on E. coli by immunofluorescence and immunohistochemistry using an anti-actin $\mathrm{mAb}$ have been inconclusive (R. J. Basaraba \& A. N. Byerly, unpublished results).

Enteropathogenic $E$. coli induces polymerization of intracellular actin at sites of attachment to small and large intestinal epithelium, producing the characteristic attaching effacing (AE) lesion. A dense plaque of polymerized actin develops at the site of attachment of AE bacteria to cell membranes (Knutton et al., 1987; Rothbaum et al., 1982; Ulshen \& Rollo, 1980). This pattern of actin accumulation is specific to enteropathogenic $E$. coli species that express the eaeA gene encoding the $94 \mathrm{kDa}$ outer-membrane protein intimin (Donnenberg et al., 1993a, b). The polymerization of intracellular actin by intimin is mediated through multiple transmembrane signalling events as the result of intimate attachment between the bacteria and host cells (Kenny \& Finlay, 1997).

Additionally, the alteration of intracellular actin cytoskeleton by some strains of $E$. coli can be mediated by secreted toxins. Cytotoxic necrotizing factor is a monomeric protein secreted by certain $E$. coli strains isolated from humans and animals with diarrhoea and extraintestinal infections (Blanco et al., 1997; Caprioli et al., 1987). Cytotoxic necrotizing factor induces assembly of intracellular F-actin stress fibres by modification of the GTP-binding protein Rho (Fiorentini et al., 1995; Oswald et al., 1994). The current study suggests that besides alteration of intracellular actin pools by $E$. coli through cell contact or secreted toxins, some pathogenic strains of $E$. coli can interact with extracellular actin. The exposure of bacteria to extracellular actin may occur as the result of host cell lysis by exotoxins like HlyA or other mediators of necrosis and inflammation. These interactions with actin may influence the potential pathogenesis of $E$. coli by masking surface antigens, increasing adhesion or modulating virulence factor expression as shown in the current studies (L'Hote et al., 1996; Olsen et al., 1989; Shen et al., 1995).

\section{ACKNOWLEDGEMENTS}

This work was supported by Agricultural Experiment Station Animal Health Fund-1433 numbers 81885 and 4-81894.

\section{REFERENCES}

Bernardini, M. L., Mounier, J., D'Hauteville, H., Coquis-Rondon, M. \& Sansonetti, P. J. (1989). Identification of icsA, a plasmid locus of Shigella flexneri that governs bacterial intra- and intercellular spread through interaction with F-actin. Proc Natl Acad Sci USA 86, 3867-3871.

Beutin, L. (1991). The different hemolysins of Escherichia coli. Med Microbiol Immunol 180, 167-182.

Bhakdi, S., Muhly, M., Korom, S. \& Schmidt, G. (1990). Effects of 
Escherichia coli hemolysin in human monocytes. J Clin Investig 85, 1746-1753.

Birnboim, H. C. \& Doly, J. (1979). A rapid alkaline extraction procedure for screening recombinant plasmid DNA. Nucleic Acids Res 7, 1513-1523.

Blanco, M., Blanco, J. E., Blanco, J. \& 7 other authors (1997). Distribution and characterization of fecal verotoxin-producing Escherichia coli (VTEC) isolated from healthy cattle. Vet Microbiol 54, 309-319.

Boehm, D. F., Welch, R. A. \& Snyder, I. S. (1990). Calcium is required for binding of Escherichia coli hemolysin (HlyA) to erythrocyte membranes. Infect Immun 38, 1951-1958.

Cano, M. L., Cassimeris, L., Fechheimer, M. \& Zigmond, S. H. (1992). Mechanisms responsible for $F$-actin stabilization after lysis of polymorphonuclear leukocytes. J Cell Biol 116, $1123-1134$.

Caprioli, A., Falbo, V., Ruggeri, F. M., Baldassari, L., Bissichia, R., Ippolito, G., Romoli, E. \& Donelli, G. (1987). Cytotoxic necrotizing factor production by hemolytic strains of Escherichia coli causing extraintestinal infections. J Clin Microbiol 25, 146-149.

Cavalieri, S. J. \& Snyder, I. S. (1982). Effect of Escherichia coli $\alpha$ hemolysin on human peripheral leukocyte viability in vitro. Infect Immun 36, 455-461.

Clinkenbeard, K. D., Mosier, D. A., Timko, A. L. \& Confer, A. W. (1989). Effects of Pasteurella haemolytica leukotoxin on cultured bovine lymphoma cells. Am J Vet Med 50, 271-275.

Clinkenbeard, K. D., Clinkenbeard, P. A. \& Waurzyniak, J. (1995). Chaotropic agents cause disaggregation and enhanced activity of Pasteurella haemolytica leukotoxin. Vet Microbiol 45, 201-209.

Confer, A. W. \& Durham, J. A. (1992). Sequential development of antigens and toxins of Pasteurella haemolytica serotype 1 grown in cell culture medium. Am J Vet Res 53, 646-652.

Cooper, J. A. (1991). The role of actin polymerization in cell motility. Annu Rev Pbysiol 53, 585-605.

Devenish, J., Rosendal, S., Johnson, R. \& Hubler, S. (1989). Immunoserological comparison of 104-kilodalton proteins associated with hemolysis and cytolysis in Actinobacillus pleuropneumoniae, Actinobacillus suis, Pasteurella haemolytica, and Escherichia coli. Infect Immun 57, 3210-3213.

Donnenberg, M. S., Tacket, C. O., James, S. P., Losonsky, G., Nataro, J. P., Wasserman, S. S., Kaper, J. B. \& Levine, M. M. (1993a). Role of the eaeA gene in experimental enteropathogenic Escherichia coli infection. J Clin Investig 92, 1412-1417.

Donnenberg, M. S., Tzipori, M., McKee, M. L., O’Brien, A. D., Alroy, J. \& Kaper, J. B. (1993b). Role of the eae gene of enteropathogenic Escherichia coli in intimate attachment in vitro and in a porcine model. $J$ Clin Investig 92, 1418-1424.

Dueland, S., Nenseter, M. S. \& Drevon, C. A. (1991). Uptake and degradation of filamentous actin and vitamin D-binding protein in the rat. Biochem J 274, 237-241.

Eberspacher, B., Hugo, F., Pohl, M. \& Bhakdi, S. (1990). Functional similarity between the hemolysins of Escherichia coli and Morganella morganii. J Med Microbiol 33, 165-170.

Fechheimer, M. \& Zigmond, S.H. (1993). Focusing on unpolymerized actin. $J$ Cell Biol 123, 1-5.

Feder, I., Chengappa, M. M., Fenwick, B. W., Rider, M. \& Staats, J. (1994). Partial characterization of Streptococcus suis type 2 hemolysin. J Clin Microbiol 32, 1256-1260.

Felmlee, T., Pellett, S. \& Welch, R. A. (1985). Nucleotide sequence of an Escherichia coli chromosomal hemolysin. J Bacteriol 163, 94-105.
Fiorentini, C., Donelli, G., Matarrese, P., Fabbri, A. \& Boquet, P. (1995). Escherichia coli cytotoxic necrotizing factor 1 : evidence for induction of actin assembly by constitutive activation of the p21 Rho GTPase. Infect Immun 63, 3936-3944.

Forestier, C. \& Welch, R. A. (1991). Identification of RTX toxin target cell specificity domains by use of hybrid genes. Infect Immun 59, 4212-4220.

Frieden, $\mathrm{C}$. (1982). The $\mathrm{Mg}^{2+}$-induced conformational change in rabbit skeletal muscle G-actin. J Biol Chem 257, 2882-2886.

Gentry, M. J., Confer, A. W., Weinberg, E. D. \& Homer, J. T. (1986). Cytotoxin (leukotoxin) production by Pasteurella baemolytica: requirement for an iron-containing compound. Am $J$ Vet Res 47, 1919-1923.

Goldberg, M. B. \& Sansonetti, P. J. (1993). Shigella subversion of the cellular cytoskeleton: a strategy for epithelial colonization. Infect Immun 61, 4941-4946.

Goldschmidt-Clermont, P. J., Lee, W. M. \& Galbraith, R. M. (1988). Proportion of circulating Gc (vitamin D-binding protein) in complexed form: relation to clinical outcome in fulminant hepatic failure. Gastroenterology 94, 1454-1458.

Haddad, J. G., Harper, K. D., Guoth, M., Pietra, G. G. \& Sanger, J. W. (1990). Angiopathic consequences of saturating the plasma scavenger system for actin. Proc Natl Acad Sci USA 87, 1381-1385.

Harris, H. E. \& Weeds, A. G. (1978). Platelet actin: sub-cellular distribution and association with profilin. FEBS Lett 90, 84-88.

Harris, H. E., Bamburg, J. R. \& Weeds, A. G. (1980). Actin filament disassembly in blood plasma. FEBS Lett 121, 175-177.

Kenny, B. \& Finlay, B. B. (1997). Intimin-dependent binding of enteropathogenic Escherichia coli to host cells triggers novel signaling events, including tyrosine phosphorylation of phospholipase C-y1. Infect Immun 65, 2528-2536.

Knutton, S., Lloyd, D. R. \& McNeish, A. S. (1987). Adhesion of enteropathogenic Escherichia coli to human intestinal enterocytes and cultured human intestinal mucosa. Infect Immun 55, 69-77.

Kocks, C., Gouin, E., Tabouret, M., Berche, P., Ohayon, H. \& Cossart, P. (1992). L. monocytogenes-induced actin assembly requires the actA gene product, a surface protein. Cell 68, 521-531.

Kolodrubetz, D., Dailey, T., Ebersole, J. \& Kraig, E. (1989). Cloning and expression of the leukotoxin gene from Actinobacillus actinomycetemcomitans. Infect Immun 57, 1465-1469.

Konig, B., Ludwig, A., Goebel, W. \& Konig, W. (1994). Pore formation by the Escherichia coli $\alpha$-hemolysin: role for mediator release from human inflammatory cells. Infect Immun 62, 4611-4617.

Koronakis, V., Cross, M., Senior, B., Koronakis, E. \& Hughes, C. (1987). The secreted hemolysins of Proteus mirabilis, Proteus vulgaris, and Morganella morganii are genetically related to each other and to the alpha-hemolysin of Escherichia coli. J Bacteriol 169, 1509-1515.

Kraig, E., Dailey, T. \& Kolodrubetz, D. (1990). Nucleotide sequence of the leukotoxin gene from Actinobacillus actinomycetemcomitans: homology to the $\alpha$-hemolysin/leukotoxin gene family. Infect Immun 58, 920-929.

Lee, W. M. \& Galbraith, R. M. (1992). The extracellular actinscavenger system and actin toxicity. $N$ Engl $J$ Med 326, 1335-1341.

Lee, W. M., Emerson, D. L., Werner, P. A. M., Arnaud, P., Goldschmidt-Clermont, P. J. \& Galbraith, R. M. (1985). Decreased serum group-specific component protein levels and complexes with actin in fulminant hepatic necrosis. Hepatology 5, 271-275. 
L'Hote, C., Berger, S. \& Karamanos, Y. (1996). O-glycosylation of fibrinogen from different mammalian species as revealed by the binding of Escherichia coli biotinylated lectins. Thromb Haemostasis 76, 710-714.

Lind, S. E., Smith, D. B., Janmey, P. A. \& Stossel, T. P. (1986). Role of plasma gelsolin and the vitamin D-binding protein in clearing actin from the circulation. $J$ Clin Investig 78, 736-742.

Manoil, C. \& Beckwith, J. (1985). TnphoA: a transposon probe for protein export signals. Proc Natl Acad Sci USA 82, 8129-8133.

Menestrina, G., Moser, C., Pellett, S. \& Welch, R. A. (1994). Poreformation by Escherichia coli hemolysin (HlyA) and other members of the RTX toxins family. Toxicology 87, 249-267.

Moayeri, M. \& Welch, R. A. (1994). Effects of temperature, time, and toxin concentration on lesion formation by the Escherichia coli hemolysin. Infect Immun 62, 4124-4134.

Olsen, A., Jonsson, A. \& Normark, S. (1989). Fibronectin binding mediated by a novel class of surface organelles on Escherichia coli. Nature 338, 652-655.

Oropeza-Wekerle, R. L., Muller, E., Kern, P., Meyermann, R. \& Goebel, W. (1989). Synthesis, inactivation, and localization of extracellular and intracellular Escherichia coli hemolysins. $J$ Bacteriol 171, 2783-2788.

Oswald, E., Sugai, M., Labigne, A., Wu, H. C., Boquet, P. \& O'Brien, A.D. (1994). Cytotoxic necrotizing factor type 2 produced by virulent Escherichia coli modifies the small GTPbinding protein Rho involved in assembly of actin stress fibers. Proc Natl Acad Sci USA 91, 3814-3818.

Pellett, S., Boehm, D. F., Snyder, I. S., Rowe, G. E. \& Welch, R. A. (1990). Characterization of monoclonal antibodies against the Escherichia coli hemolysin. Infect Immun 58, 822-827.

Pollard, T. D. \& Cooper, J. A. (1986). Actin and actin-binding proteins : a critical evaluation of mechanisms and function. Annu Rev Biochem 55, 987-1035.

Rennie, R. P., Freer, J. H. \& Arbuthnott, J. P. (1974). The kinetics of erythrocyte lysis by Escherichia coli hemolysin. $J$ Med Microbiol 7, 189-194.

Rothbaum, R., McAdams, A. J., Giannella, R. \& Partin, J. C. (1982). A clinicopathologic study of enterocyte-adherent Escherichia coli: a cause of protracted diarrhea in infants. Gastroenterology 83, 441-454.

Shen, W., Steinruck, H. \& Ljungh, A. (1995). Expression of binding of plasminogen, thrombospondin, vitonectin, and fibrinogen, and adhesive properties by Escherichia coli strains isolated from patients with colonic diseases. Gut 36, 401-406.

Smith, D. B., Janmey, P. A. \& Lind, S. E. (1988). Circulating actin-gelsolin complexes following oleic acid-induced lung injury. Am J Pathol 130, 261-267.

Spudich, J. A. \& Watt, S. (1971). The regulation of rabbit skeletal muscle contraction. J Biol Chem 246, 4866-4871.

Stossel, T. P. (1978). Contractile proteins in cell structure and function. Annu Rev Med 29, 427-457.

Theriot, J. A. (1994). Regulation of the actin cytoskeleton in living cells. Cell Biol 5, 193-199.

Trifillis, A. L., Donnenberg, M. S., Cui, X., Russel, R. G., Utsalo, S. J., Mobley, H. L. T. \& Warren, J.W. (1994). Binding and killing of human renal epithelial cells by hemolytic P-fimbriated Escherichia coli. Kidney Int 46, 1083-1091.

Ulshen, M. H. \& Rollo, J. L. (1980). Pathogenesis of Escherichia coli gastroenteritis in man - another mechanism. $N$ Engl J Med 302, 99-101.

Vasconcellos, C. A., Allen, P. G., Wohl, M. E., Drazen, J. M., Janmey, P. A. \& Stossel, T. P. (1994). Reduction in viscosity of cystic fibrosis sputum in vitro by gelsolin. Science 263, 969-971.

Waurzyniak, J., Clinkenbeard, K. D., Confer, A. W. \& Srikumaran, S. (1994). Enhancement of Pasteurella haemolytica leukotoxic activity by bovine serum albumin. Am J Vet Res 155, 1267-1274.

Welch, R. A. \& Pellett, S. (1988). Transcriptional organization of the Escherichia coli hemolysin genes. J Bacteriol 170, 1622-1630.

Welch, R. A., Forestier, C., Lobo, A., Pellett, S., Thomas, W. J. \& Rowe, G. E. (1992). Synthesis and function of the Escherichia coli hemolysin and related RTX exotoxins. Microbiol Immunol 105, 29-36.

Received 16 December 1997; revised 27 February 1998; accepted 9 March 1998. 